\title{
Osteoporosis, Skin Collagen, and Androgen
}

\author{
MARTIN M. BLACK, $†$ M.B., M.R.C.P. ; SAM SHUSTER,* M.B., PH.D., F.R.C.P. ; EVA BOTTOMS, $\ddagger$ B.SC.
}

British Medical fournal, 1970, 4, 773-774

\begin{abstract}
Ummary: Total skin collagen was found to be decreased in untreated patients with osteoporosis, particularly women, but increased after treatment with androgens in women. Decreased body collagen may possibly be a primary defect in osteoporosis, while androgens may increase total skin collagen.
\end{abstract}

\section{Introduction}

McConkey et al. (1963) noticed the association between thin transparent skin and osteoporosis, and Shuster and Bottoms (1963a) suggested that "studies of the absolute collagen content of skin may help to clarify our views on collagenolytic diseases such as osteoporosis." Skin collagen can be measured in absolute terms by relating it to skin surface area (Shuster and Bottoms, 1963a; Shuster et al., 1967a, 1967b). We now present our findings on total skin collagen in osteoporosis and the effect of treatment with androgen.

\section{Methods}

Patients were referred from a number of different centres over a period of years. The diagnosis was made radiologically and by the findings of a normal serum concentration of calcium, inorganic phosphate, and alkaline phosphatase. Men and women aged from 28 to 84 years were studied in two groups: (1) no treatment with androgens (15 patients) and (2) treatment with androgens (24 patients). The type of androgen, dose, and duration of treatment were too diverse for further analysis. A number of the patients had, for example, already received various androgens from their family doctors before being referred to hospital, and the precise dose and frequency was not always clear.

Total skin collagen was measured as described by Shuster and Bottoms (1963a): skin biopsies were taken from the midpoint of the extensor aspect of the forearm with a high-speed punch using a 5-mm. head. The biopsies were defatted in acetone and dried to constant weight. After hydrolysis the hydroxyproline content was measured by the method of Woessner (1961). Skin collagen calculated from the hydroxyproline content was expressed in relation to the surface area of the biopsy, since this has been shown to be the most satisfactory way to measure total skin collagen (Shuster and Bottoms, 1963a). The results matched for age and sex are compared with the results from 73 men and 62 women which include our previously published normal data (Shuster and Bottoms, 1963a; Shuster et al., 1967a, 1967b).

\section{Results}

In group 1 (no androgen treatment) the total skin collagen was less in patients with untreated osteoporosis than in controls (Fig. 1) but this difference just fell short of statistical significance, taking the group as a whole $(P>0.05)$. Total skin collagen was, however, significantly less than normal in

\footnotetext{
- Professor of Dermatology.

† Registrar

Senior Research Associate

Present address: Institute of Dermatology, London W.C.2.

University Department of Dermatology, Newcastle upon Tyne NE1 4LP
}

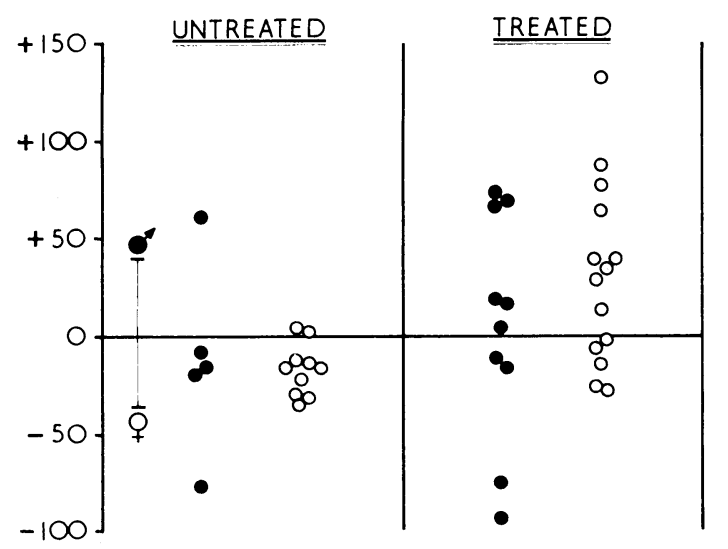

FIG. 1.-Total skin collagen (as collagen per unit surface area $\left.\left(\mu \mathrm{g} . / \mathrm{mm}^{2}\right)\right)$ in osteoporosis and the effect of androgen treatment. The results are all expressed as a difference from normal subjects of the same age and sex.

untreated women with osteoporosis $(P<0.01)$. In group 2 (androgen-treated) the total skin collagen was greater in patients who had received androgen than in those with untreated osteoporosis (Fig. 1). This was due mainly to the women $(P<0.001)$, since there was no significant change in the men $(P>0.5)$. This increase was also apparent when women treated with androgens were compared with normal women (Fig. 1, $\mathrm{P}<0.05$ ).

\section{Discussion}

The non-mineral portion of bone is mainly collagen and most of the body's collagen is found in the skin and bone. McConkey et al. (1963) were the first to notice the association between transparent skin and osteoporosis, and we have now shown that total skin collagen is indeed decreased in patients with osteoporosis, particularly in women. Interestingly corticosteroids also decrease skin collagen (Shuster et al., 1967a) and the fragile skin of corticosteroid purpura (Scarborough and Shuster, 1960) is often associated with osteoporosis (McConkey et al., 1962). Again the fragile skin of patients with osteogenesis imperfecta is also low in collagen (Stevenson et al., 1970). Hence possibly osteoporosis and some other bony diseases are due to a generalized abnormality of collagen of which demineralization is a consequence.

The increase in skin collagen after androgen treatment is of great theoretical interest, though in the patients we studied the variety of therapeutic regimens was too great to relate the change to dose or type of androgen. Skin collagen decreases with age, but at all ages skin collagen is appreciably greater in men than in women (Shuster and Bottoms, 1963a), and the same is true of mouse and rat skin (Shuster and Bottoms, 1963b, 1967; Dickerson and John, 1964). The present observations suggest this difference may be androgen determined. The increased skin collagen content which we have recently found in women with hirsuties may be explained in this way (Shuster et al., 1970).

We are grateful to the Medical Research Council for a grant to S. S.

Requests for reprints to Professor S. Shuster. 


\title{
REFERENCES
}

Dickerson, J. W. T., and John, P. M. V. (1964). Biochemical fournal, 92, 364 McConkey, B., Fraser, G. M., and Bligh, A. S. (1962). Qicarterly fournal of Medicine, 31, 419 .

McConkey, B., Fraser, G. M., Bligh, A. S., and Whiteley, H. (1963). Lancet, 1, 693.

Scarborough, H., and Shuster, S. (1960). Lancet, 1, 93.

Shuster, S., Black, M. M., and Bottoms, E. (1970). British Medical Journal, 4 , In same issue.
Shuster, S., and Bottoms, E. (1963a) Clinical Scienci, 25, 487.

Shuster, S., and Bottoms, E. (1963b). Nature, 199, 192.

Shuster, S., and Bottoms, E. (1967). Nature, 214, 599.

Shuster, S., Raffle, E. J., and Bottoms, E. (1967a). Lancet, 1, 525.

Shuster, S., Raffle, E. J., and Bottoms, E. (1967b). British fournal of Dermatology, 79, 456.

Stevenson, C. J., Bottoms, E., and Shuster, S. (1970). Lancet, 1, 860

Woessner, J. F. (1961). Archives of Biochemistry and Biophysics, 83, 440

\section{Restless Legs Syndrome, with Particular Reference to its Occurrence after Gastric Surgery}

\author{
N. K. BANERJI, ${ }^{*}$ M.D., PH.D. ; L. J. HURWITZ, $†$ M.D., F.R.C.P.ED.
}

\begin{abstract}
ummary: There is a higher incidence of restless legs syndrome (Ekbom's syndrome) in patients after gastric surgery $(11.3 \%)$ and with diabetes mellitus $(17.0 \%)$ and uraemia $(17.3 \%)$ than in patients who have been diagnosed as having a psychonoeurosis $(4.0 \%)$ and in controls $(2.0 \%)$. Three patients with malabsorption syndrome complained of restless legs, but these patients had abnormal neurological signs. The incidence after gastric surgery and in diabetes mellitus and uraemia remained high even when patients with any abnormal neurological signs were excluded.
\end{abstract}

\section{Introduction}

"Wherefore to some, when being a Bed they betake themselves to sleep, presently in the Arms and Leggs Leapings and Contractions of the Tendons, and so great a Restlessness and Tossings of their Members ensue, that the diseased are no more able to sleep, than if they were in a Place of the greatest Torture"- Thomas Willis. Since this description by Thomas Willis (1685) cases with such symptoms have been reported under a variety of names, including "anxietas tibiarum" (Wittmaack, 1861), "leg jitters" (Allison, 1943), and "asthenia crurum paraesthetica" (Ekbom, 1944). It was Ekbom (1944, 1945) who recalled the problem and elucidated the occurrence and character of the "restless legs" syndrome which is often named after him. The syndrome is thought to be not uncommon, but Ekbom (1960) reported a higher incidence in patients after gastric surgery than in the general healthy population. There have been relatively few reports concerning its incidence in patients after gastric surgery compared with that in patients with some other illnesses.

\section{Patients and Methods}

Five groups of patients have been studied (Table I). The 106 who had been treated by gastric surgery for peptic ulcer had had a variety of standard operations, mainly partial gastrectomy. These patients were attending for review at a followup clinic in the Royal Victoria Hospital, Belfast. Thirty-one of the 43 with malabsorption syrdrome were referred from outpatient departments, but the remaining 12 had some neurological illness requiring hospital treaiment. The patients with diabetes mellitus were well controlled and were attending the metabolic outpatient department, and the uraemic patients had chronic renal disease. The patients with psychoneurosis were interviewed either at a psychiatric day hospital or at the psychiatric outpatient department while the control group

\footnotetext{
* Registrar.

+ Consultant Neurologist.

Department of Neurology, Royal Victoria Hospital, Belfast BT12 6BA.
}

comprised healthy medical, nursing, and domestic staff and also patients attending the neurological outpatient department who had complained of headache and had no neurological signs.

Patients after gastric surgery and those with malabsorption, diabetes, uraemia, and psychoneurosis were examined personally for neurological signs. A questionnaire (Table II) was completed for each subject, a diagnosis of restless legs syndrome being made if affirmative answers were given to questions one to four and negative answers to questions six to nine. It is emphasized that the distinction made by Ekbom (1944) between restless legs and two similar syndromes-acroparaesthesiae and nocturnal burning feet-was maintained and a diagnosis of restless legs syndrome was not accepted if the patient's symptoms were of tingling, pins-and-needles, cramps, or burning sensation.

\section{Results}

The incidence of restless legs was highest in the gastric surgery, diabetic, and uraemic patients (Table I). In four-two diabetic and two uraemic patients - the syndrome had existed before the onset of the disease. The type of gastric surgery was not related to the presence or absence of restless legs. Increased age of the patient and the length of time since the

\begin{tabular}{|c|c|c|c|c|c|c|c|c|c|}
\hline \multirow{2}{*}{ Patient Group } & \multirow{2}{*}{ No. } & \multicolumn{2}{|c|}{ Sex } & \multicolumn{2}{|c|}{ Age (years) } & \multicolumn{4}{|c|}{ Restless Legs Syndrome } \\
\hline & & $M$. & F. & Mean & Range & No. & $\because$. & M. $\left("{ }^{\prime}\right)$ & F. $\left(0^{\prime}\right)$ \\
\hline $\begin{array}{l}\text { Gastric surgery } \\
\text { Malabsorption } \\
\text { syndrome } \\
\text { Diabetes mellitus } \\
\text { Uraemia } \\
\text { Psychoneurosis } \\
\text { Control . . }\end{array}$ & $\begin{array}{r}106 \\
43 \\
53 \\
52 \\
50 \\
50\end{array}$ & $\begin{array}{l}79 \\
19 \\
26 \\
26 \\
23 \\
23\end{array}$ & $\begin{array}{l}27 \\
24 \\
27 \\
26 \\
27 \\
27\end{array}$ & $\begin{array}{l}54 \cdot 1 \\
50 \cdot 4 \\
53 \cdot 2 \\
56 \cdot 3 \\
54 \cdot 4 \\
50 \cdot 2\end{array}$ & $\begin{array}{l}32-73 \\
20-72 \\
20-79 \\
20-72 \\
24 \quad 72 \\
24-66\end{array}$ & $\begin{array}{r}12 \\
3 \\
9 \\
9 \\
2 \\
1\end{array}$ & $\begin{array}{r}11 \cdot 3 \\
6 \cdot 9 \\
17 \cdot 0 \\
17 \cdot 3 \\
4 \cdot 0 \\
2 \cdot 0\end{array}$ & $\begin{array}{r}12 \cdot 6 \\
10.5 \\
7 \cdot 7 \\
11.5 \\
0 \\
0\end{array}$ & $\begin{array}{r}7 \cdot 4 \\
4 \cdot 1 \\
25 \cdot 9 \\
23 \cdot 1 \\
7 \cdot 4 \\
3 \cdot 7\end{array}$ \\
\hline
\end{tabular}

TABI.E II

Each patient was asked to answer the following questions:

1. Do you have any unpleasant feeling in the legs which keeps you from sleeping? If yes, describe the feeling

2. Is the unpleasant feeling completely relieved by walking about?

3. Do you have to move your legs when you have the feeling?

4. Does it appear on going to bed at night or sitting in the evenings?

5. Does the feeling affect any other parts of your body besides the legsfor instance the arms?

6. Is the feeling like a cramp which you might have while running, working

7ound the house, or doing some exercise?

8. Is it similar to the sensation (pins-and-needles) felt in a leg which has gone to sleep?

9. It is a burning sensation in the feet which gets better after placing the feet in the cooler part of the bed or outside the blankets? 